\title{
NBSIR 73-194 (R) \\ Performance of Cancellation Inks on Partially Tagged Gravure Postage Stamps
}

E. L. Graminski and M. R. Brockman

Paper Evaluation Section

Product Evaluation Technology Division Institute for Applied Technology

National Bureau of Standards

Washington, D. C. 20234

April 15, 1973

Final Report

USPS NBS Letter Agreement 72-1-01619

Prepared for

U. S. Postal Service

Washington, D. C. 20260 



\title{
PERFORMANCE OF CANCELLATION INKS \\ ON PARTIALLY TAGGED GRAVURE POSTAGE STAMPS
}

\author{
E. L. Graminski and M. R. Brockman
}

Paper Evaluation Section

Product Evaluation Technology Division

Institute for Applied Technology

National Bureau of Standards

Washington. D. C. 20234

April 15, 1973

Final Report

USPS NBS Letter Agreement 72-1-01619

Note:

This document has been prepared for the use of the U.S. Postal Service. Responsibility for its further use rests with that agency.

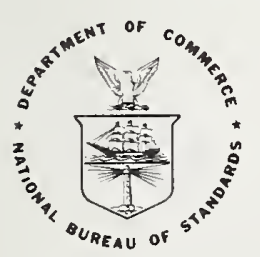

U. S. DEPARTMENT OF COMMERCE, Frederick B. Dent, Secretary 

CONTENTS

Page

1. SUMMARY • • . . . . . . . . . . . . . . . . 1

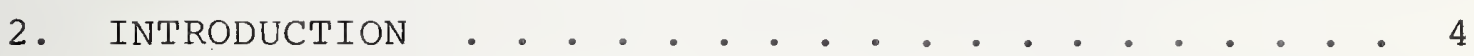

3. RESULTS AND DISCUSSION • • • • • • • • • • • . . 7

3.1 Evaluation of Cancellation Inks on the looth Anniversary Mail Order Stamp . . . . . 7

3.2 Modification of Regular PS Cancellation

3.3 Evaluation of Rolier Ink $44-2$ for Use in Standard Facer-Cancelers. . . . . . . . 10

3.4 Test for Ink Penetrability . . . . . . . . . 11

3.5 Development of an Ink Erasure Test . . . . . 12

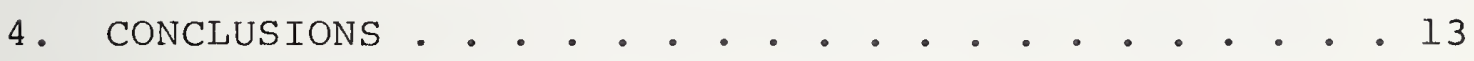

5. RECOMMENDATIONS . . . . . . . . . . . . . . . . 14

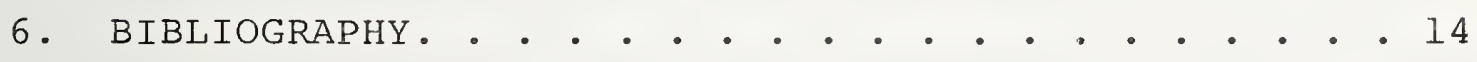





\section{SUMMARY}

When the United States Postal Service initiated the tagging of stamps by overprinting with phosphor ink, there was some indication that cancellation marks made with regular Postal Service (PS) cancellation ink were easier to rub off or erase. Erasure became still easier with the introduction of postage stamps printed by the gravure process. Cancellation ink performance might deteriorate still further with the introduction of new cancellation inks in the currently developed high speed facer-canceling machines.

As a consequence, the U.S. Postal Service requested the National Bureau of Standards (NBS) to (1) resolve the reasons for the poor performance of regular PS cancellation ink on gravure stamps, (2) to propose possible means of improving the cancellation ink performance, and (3) to evaluate the performance of the new facer-canceler roller inks on both intaglio and gravure stamps.

Intaglio printing is produced from plates on which the image is sunken below the surface of the plate as distinguished from letterpress (relief) or planography (flat plane). Included in intaglio printing is rotogravure, as the image consists of regular (screen) or irregular (grain) etched depressions.

The following materials were involved in this study:

(1) Stamp paper for gravure printing of postage stamps. This is a coated paper.

(2) Stamp paper for intaglio printing of postage stamps (uncoated).

(3) Regular (currently used) PS cancellation ink.

(4) Two roller inks, designated in this report as 400 and 4-2.

The roller inks are not yet in use, but they probably will be in use soon. Porous rollers are saturated with these inks and serve as the ink well in new high-speed facer-canceling machines under development.

(5) Phosphor tagging inks. 

Work done initially on this project at NBS showed that the gravure tag ink causes poor resistance to erasure of cancellation marks made with regular PS cancellation ink on gravure postage stamps [1]. When the looth Anniversary Mail Order (AMO) stamp was printed by the gravure process, only a portion of the stamp was tagged in order to allow evaluation of both PS and roller cancellation inks on tagged and untagged portions.

Stamps affixed to test mail were hand canceled with regular PS cancellation ink and roller inks 44-2 and 400, and the resistance to erasure and chemical eradication was evaluated. The performance of regular PS cancellation ink was unsatisfactory even in the untagged portion of the stamps because of its poor resistance, to erasure. The results indicated that the regular PS cancellation ink must be reformulated or modified in order to perform satisfactorily on gravure postage stamps.

Although the regular PS ink did not have good resistance to erasure, the roller inks resisted erasure extremely well by virtue of pigment penetration into the stamp paper. Cancellation marks made with the roller inks could not be remored from the untagged portion by erasing without defacing the stamp. As the vehicle of regular PS ink penetrates stamps readily, the performance of the ink might be improved by the addition of a pigment soluble in the ink vehicle.

The addition of 1 percent by weight of a specific dye improved the performance of regular PS ink. The dye and vehicle penetrated gravure postage stamp ink, and cancellation marks made with the modified ink on the AMO stamp could not be erased without defacing the stamp in the areas having no tag ink. In addition, the modified ink was evaluated in standard facer-cancelers with satisfactory results.

While roller ink 44-2 performs satisfactorily in the new high-speed facer-canceler, a similar ink supplied by the manufacturer of roller ink 44-2 did not perform satisfactorily as an ink for standard facer-cancelers.

In the absence of satisfactory tests for ink penetrability and resistance to erasure, tests were developed to evaluate these properties using commercially available apparatus involving a minimum of operator variables. 

The results of this study indicate that all gravure stamps should be tagged on only a portion of the stamp and that the regular PS ink should be reformulated or modified as described above for satisfactory performance on gravure postage stamps. 



\section{INTRODUCTION}

Problems in stamp cancellation appeared simultaneously with the advent of stamp tagging with phosphor inks. There was some evidence that the cancellation marks were easier to erase or rub off of stamps overprinted with tag ink. In an effort to overcome this problem, the Bureau of Engraving and Printing (BEP) formulated an ink which performed better than the postal Service cancellation ink with respect to erasure. However, the ink gelled in areas of high relative humidity, and this resulted in damage to the ink pump mechanism in facer-canceler machines. The gelling of the ink and the decline in cancellation ink performance were not resolved nor were the issues pursued further until now. Recent inquiries revealed that the BEP cancellation ink was a moisture set ink, and it could be expected to gel in regions of high humidity.

The problems with cancellation ink performance became acute when stamps were printed by the gravure process. Cancellation marks were easily erased or rubbed off from many of the stamps. It was apparent that either the stamp paper, stamp irks, tag ink, or a combination of these was causing the regular PS cancellation ink to perform unsatisfactorily.

The problems with stamp cancellations could become greater with the introduction of new inks in the high-speed facer-canceling machines that are under development. The new facer-cancelers will use a porous roller impregnated with ink instead of an ink fountain. When the ink in the roller is consumed, the roller simply is replaced with a new roller that is full of ink. This is a much cleaner procedure.

In view of the existing and impending problems with cancellation ink performance on gravure stamps, the U.S. Postal Service requested the National Bureau of Standards to (1) determine the reasons for the poor performance of regular PS cancellation ink on gravure stamps, (2) propose possible approaches to improving the performance of the ink, and (3) evaluate the performance of the new roller inks on both intaglio and gravure stamps.

Regular PS cancellation ink is a quick-set ink. Quickset inks are based on a two phase medium that separates in a filtering medium such as paper. A thin varnish drains into the paper leaving the viscous constituent in the ink to set on the surface. 

The new high-speed facer-cancelers under development vill employ rollers saturated with ink as the ink well. Unlike the regular PS ink, pigment as well as the vehicle of roller inks penetrate into the stamp.

Previous work has shown [1] that the tag inks are a major cause of poor performance of cancellation inks on intaglio, and especially gravure, stamps. The vehicle of the gravure tag ink is an excellent film former. The excellent film forming characteristic of the tag ink culminates in two undesirable features. First, the tag ink forms a barrier on the surface of gravure stamps preventing, or retarding, penetration of ink into the stamp; and secondly, the tag ink reduces the macroroughness of gravure stamp surfaces resulting in poorer adhesion of ink plugs to the surface of gravure stamps. As a consequence, cancellation marks made with either regular PS or roller inks can be erased readily because of poor adhesion of ink plugs to the stanp surface or poor penetration of ink and vehicle into the stamp paper.

Since the tag ink covers the entire stamp, it was suggested chat only a portion of the stamp be printed with tag ink [1]. Therefore, only a portion of the stamp would have all the uncesirable features produced by the tag ink. The 100th I.nniversary Mail Order (AMO) stamp issued in september 1972 was tagred on only a portion of the surface to determine whether cancellation performance could be improved by partial tagging. The tagged area consisted of a bar, approximately $3 / 8$ inch wide running vertically through the center of the stamp.

In the evaluation of cancellation inks on the AMO stamp, an interesting discovery was made. Whenever ink pigment penetrated gravure postage stamp ink in the untagged areas, cancellation marks could not be erased without defacing the stamp. Apparently, gravure stamp inks have a much lower abrasion resistance than the gravure tag ink, and the stamp is easily defaced by erasing in the stamo areas having no tag ink.

Since the vehicle of regular PS cancellation ink readily penetrates through gravure postage ink films, the performance of the regular PS ink might be improved by the addition of a pigment soluble in the ink vehicle. Even though the ink plug still could be erased easily from the surface, a residue 

would remain after erasure because of the vehicle-soluble rigment having penetrated into the stamp paper. Complete removal of the cancellation mark would not be possible in the untagged portion of a gravure stamp without abrading the ink and defacing the stamp. Contact with the manufacturer of the regular PS cancellation ink revealed that three dyes were known to be soluble in the vehicle. These three dyes were then used to modify the regular PS ink and their performance was evaluated on the AMO stamp. In addition to evaluating the modified ink, a facsimile of one roller ink, 44-2, was evaluated for possible use in the standard facercanceler.

The absence of good ink penetrability and ink erasure tests became evident during the course of this study. As the performance of cancellation inks is so dependent on these two properties, tests were developed to evaluate them. 



\section{RESULTS AND DISCUSSION}

3.1 Evaluation of Cancellation Inks on the looth Anniversary Mail Order Stamp

Three inks were used in this investigation, regular PS and roller inks 400 and 44-2. The evaluation consisted of determining the resistance to erasure and chemical eradication on hand-canceled and machine-canceled test letter mail. The test letter mail consisted of $41 / 8 \times 9$ 1/2 inch white envelopes stuffed with a single $81 / 2 \times 11$ inch sheet of bond paper.

AMO stamps were affixed to test letter mail and were hand canceled with light to medium and regular to heavy cancellations. Resistance to erasure was determined 2, 24, 48 , and 72 hours after the cancellations were made. The erasing procedure was the same as one would use in erasing a typing error using a \#40E commercial pencil eraser. The object was to remove the cancellation mark from the entire stamp without defacing the stamp. If any part of the stamp became defaced as a result of erasing the cancellation mark, the cancellation ink was considered to have excellent resistance to erasure. The results are summarized in Table 1.

Erasure resistance was poor for regular PS cancellation ink on both the tagged and untagged portion of the stamp. The cause for the unsatisfactory resistance to erasure is due to poor adhesion of the ink plug to the smooth surface. This indicates that regular PS cancellation ink must be reformulated before it can perform satisfactorily on gravure stamps regardless of the coverage by tag ink.

Cancellation inks 400 and $44-2$ performed extremely well on the AMO stamp. Both inks penetrated through the untagged stamp ink, and cancellation marks could not be erased without damaging the stamp ink. However, the cancellation marks could be easily erased from the tagged portion of the stamp even after 72 hours following cancellation. Apparently, gravure stamp inks have a lower abrasion resistance than gravure tag ink with the result that the stamp ink is easily damaged when erased.

Resistance to chemical eradication was evaluated on light to medium and regular to heavy hand cancellations made on the AMO stamp affixed to test mail. Three commercial ink 

cradicators and one laundry bleach were tested and were applied three times to the cancellation marks. The tests were performed 48 hours after cancellation to allow sufficient time for the ink to set. The results are given in Table 2.

Resistance to chemical eradication was excellent for the regular PS cancellation ink, very good for ink 44-2, and fair to poor for ink 400 . These results agree with previous results [1] that ink 400 does not have satisfactory resistance to chemical eradication and would be an unsatisfactory cancellation ink.

\subsection{Modification of Regular PS Cancellation Ink with Dyes}

Three commercial dyes, designated A, B, and C, were claimed by the manufacturer of the regular PS cancellation ink to be soluble in the ink vehicle. The regular cancellation ink was modified by adding the appropriate quantity of dye to the regular PS cancellation ink so that it contained 10 weight percent of the dye.

The ink penetrability and erasure tests used in this investigation are described in sections 3.4 and 3.5 of this report. The results indicated that dye $A$ had the greatest potential for successful modification of regular PS cancellation ink. Dye B was intermediate, and dye C was completely unsatisfactory (Tables 3 and 4 ). Dye A caused excessive feathering, an appreciable change in the rheology of the PS cancellation ink, and is relatively expensive (\$5.77/lb.), so less dye was used in subsequent modifications. Additional ink samples were prepared containing 1,2 , and 5 percent of dyes $A$ and $B$ and one sample containing $l$ percent of dye $C$.

Ink penetrability and erasure tests were performed on the modified inks. The results are given in Tables 3 and 4. The ink containing only 1 percent of dye $C$ was completely unsatisfactory by virtue of its very poor resistance to erasure. The resistance to erasure of regular ink modified with 1,2 , and 5 percent of dye $B$ was only slightly better than the ink modified with dye $C$ and must be considered unsatisfactory. 

The use of smaller quantities of dye A in regular PS cancellation ink resulted in improved performance. Feathering decreased substantially when only 1 or 2 percent of dye $A$ was used. Furthermore, the decrease in amount of dye used did not decrease resistance to erasure, and ink penetrability improved. In view of the apparent improvement in the performance of regular PS cancellation ink when modified with 1 percent of dye A, its performance on the AMO stamp was evaluated. Test letter mail was hand canceled with light to medium and regular to heavy cancellations. Three properties were evaluated: (1) resistance to erasure, (2) resistance to chemical eradication, and (3) effect of water soaking. Resistance to erasure and chemical eradication were done as described in section 3.1 of this report. The results are given in Tables 5,6 , and 7 .

The resistance to chemical eradication of regular PS ink is excellent and there was no reason to believe that its resistance would decrease due to the addition of dye. The important requirement, however, is for the residue, after erasure, to be resistant to chemical eradication. If the residue is not resistant to chemical eradication, then a combination of erasure and chemical eradication could result in gocd removal of cancellation marks from gravure stamps. Therefore, resistance to chemical eradication was determined before and after the cancellation marks were erased as thoroughly as possible without damaging the stamp.

The effect of water soaking on the cancellation mark was done because philatelists frequently remove stamps by soaking. Therefore, cancellations must not bleed or fade during a 24 hour water soak. The performance of regular PS cancellation ink, with and without dye A, was determined for 15 minute and 24 hour water soaks.

Resistance to erasure and resistance to chemical eradication before and after erasure was very good for the ink modified with dye A. Water soak produced no bleeding or fading after 15 minutes or 24 hours. The results indicate that modification of regular PS cancellation ink with a dye soluble in the ink vehicle is one method for improving the performance of the ink on gravure stamps.

A natural question with respect to the modification of regular PS cancellation ink is whether the modification will affect the ink's performance in the facer-canceies. une 

gallon of modified regular PS ink was prepared for evaluation in facer-cancelers at two post offices. Sufficient ink was available for two facer-cancelers to operate full time for at least one week.

The ink performed satisfactorily in the standard facercancelers with no major complications. When cancellation marks are heavy, some feathering is apparent on certain envelopes. Feathering occurs with the regular PS ink as well, but because of the dye used in ink modification, the feathering is more obvious with the modified ink. There is no indication that the modified ink penetrates through the envelope and into the envelope contents. As with all other cancellation inks evaluated to date, the heavier the cancellation mark, the more difficult it becomes to erase the cancellation mark.

\subsection{Evaluation of Roller Ink 44-2 for Use in Standard Facer-Cancelers}

Since roller ink 44-2 performed excellently on the AMo stamp, à sample of this ink was obtained from the manufacturer for evaluation of its use in the standard facer-cancelers. The ink received from the manufacturer was not identical to that obtained by squeezing ink from the rollers because a change in the ink occurs during roller manufacture. Nevertheless, the ink supplied was considered to be a reasonable facsimile of what the manufacturer could supply for facercancelers.

Ink penetrability tests indicated that there was a great difference between the ink sample provided by the manufacturer and the ink obtained by compressing the rollers. No penetration occurred after 2 hours on gravure stamp paper printed with gravure postage ink. On the average, penetration occurred with ink obtained from rollers in 993 seconds. Because of the lack of penetrability, cancellation marks on gravure stamps made with the ink obtained from the manufacturer were still wet after 48 hours, but should have set within 24 hours.

The results indicate that roller ink 44-2 as supplied by the manufacturer of the rollers would be unsatisfactory for use in standard facer-cancelers. 



\section{4 Test for Ink Penetrability}

The method consisted of placing a drop of ink on the surface of stamp papers and determining the time required for the ink to penetrate through the paper to the opposite side of the sheet. Previously, ink penetrability on stamps and stamp papers was assessed by determining the time required for ink to penetrate over a defined circular area [1]. The difficulty with the previous test was the unusually long time interval required for complete penetration. Three inks, regular PS and roller inks $44-2$ and 400 , were used in this evaluation. At least 20 determinations were made for each ink on each paper. If no penetration occurred within 3600 seconds, penetration was assumed to have not occurred at that test site. The time was recorded if penetration occurred within 3600 seconds. As a consequence, the number of determinations in some cases is listed as less than 20. This signifies that the ink penetrated poorly into the paper. The results are given in Table 8 .

The data indicate that the time for initial penetration is a good measure of the penetrability of inks. It is quite apparent that the porosity of the surface of gravure paper, especially after printing with postage stamp and/or tag ink, varies greatly over the surface as indicated by the large standard deviation. A large dispersion such as this requires a large number of determinations if the data are to be meaningful, and to ascertain whether differences between inks and between papers are significant.

Neither intaglio stamp ink nor intaglio tag ink individually reduce the penetrability of cancellation inks to the point of being detrimental to the performance of the cancellation inks. When intaglio postage paper is printed with both intaglio postage stamp and intaglio tag inks, a great decrease in cancellation ink penetrability occurs. Normally, the postage stamp ink coverage on intaglio stamps is never complete, and the combination of postage stamp and tag inks usually does not create a barrier to cancellation inks. On occasion, the ink coverage on intaglio stamps is great enough to cause poor cancellation ink performance. The llc Air Mail stamp (Figure 1, NBS Report.10 9l1) had a high ink coverage in the red portion of the stamp creating a condition whereby cancellation riarks made with regular PS cancellation ink were easily erased. If the stamps were tagged on only a portion of the stamp, this situation would not have arisen and cancellation marks valc have been difficult to remove on at least a portion of the stamps. 

A somewhat different situation exists with gravure stamps. When gravure tay ink is printed over gravure postage stamp ink, cancellation inks penetrate more readily than they do if the postage paper is printed with only tag ink. This behavior also was observed on gravure postage stamps (page 9, NBS Report 10 911).

\subsection{Development of an Ink Erasure Test}

Resistance to erasure, when the erasure is done manually, is subject to variability among individuals and is semiquantitative at best. There was a great need for an erasure test that would be independent of operator differences and could be performed by any laboratory on equipment commercially available.

Eārly results indicated that a commercial abrader might evaluate resistance to erasure satisfactorily. It was observed that gravure postage stamp ink, printed on gravure postace stamp paper, showed evidence of abrasion at about 2000 cycles on the commercial abrader. The abrasion was accomplished with standard rubber wheels available from the abrader manufacturer. The stamp paper printed with postage stamp ink was hand canceled and subjected to 2000 cycles on the abrader. Those cancellation inks easily erased manually were completely removed within 1000 cycles. Those inks which were difficult or impossible to erase manually were not removed within 2000 cycles on the abrader. If the abrasion was continued beyond 2000 cycles, the postage stamp ink was abraded excessively, indicating that the cancellation marks could not be removed without damaging the postage ink film.

There is one operation in the erasure procedure which is affected by operator variability. Hand cancellation of the paper prior to abrasion can vary from one operator to another. Consequently, a rubber stamp was procured consisting of waving lines 1 millimeter wide in a circle with a $43 / 16$ inch diameter, which was identical to the diameter of the platform of the abrader. An impression was made with the cancellation ink to be tested on the stamp paper printed with gravure postage stamp ink using approximately $2 \mathrm{~kg}$ pressure, and allowed to set for 48 hours. The circle was then cut out, placed on the table of the abrader, clamped, and abraded for 2000 cycles. The abraded specimen was removed from the abrader and inspected. If the cancellation ink was not completely removed after 2000 revolutions, the ink was considered to have an acceptable resistance to erasure. When the cancellation ink was completely removed in 2000 revolutions, the ink was considered to have an unacceptable resistance to erasure. 

4. CONCHUSTONS

1. Bar tagging of gravure stamps results in an improvement in cancellation ink performance when the ink pigment penetrates into the stamp paper. Regular PS cancellation ink does not perform satisfactorily on bar tagged gravure stamps indicating the regular PS cancellation ink must be reformulated or modified.

2. Regular PS cancellation ink can be modified by the addition of a specific dye that is soluble in the vehicle. The pigment penetrates through the postage stamp ink of bar tagged stamps and into the stamp paper. When the ink plug from the regular PS cancellation ink is removed by erasure, a residue remains which cannot be removed by erasure without defacing the stamp.

3. Roller ink 44-2, as supplied by the manufacturer, would not be an acceptable ink for use in standard facercancelers.

4. Satisfactory tests have been developed for evaluating the pentrability and resistance to erasure of cancellation inks. 



\section{RECOMMENDATIONS}

1. All gravure stamps should be bar tagged in preference to tagging over the entire stamp surface.

2. The regular PS ink should be modified so that the pigment penetrates through the postage stamp ink and into the postage stamp paper.

\section{BIBLIOGRAPHY}

1. Graminski, E. L. and Brockman, M. R., NBS Report 10911 , Performance of Cancellation Inks on Intaglio and Gravure Postage Stamps, September 18, 1972. 

Table 1. Erasability of cancellation marks from the $8 \dot{c}$ Mail Order Commemorative stamp.

Time After Cancellation hrs.

2
24

48

72

2

24

$4 \varepsilon$

72
Cancellation Ink

\begin{tabular}{|c|c|c|}
\hline Regular & 400 & $44-2$ \\
\hline $\begin{array}{l}\text { Resistance } \\
\text { to Medium }\end{array}$ & $\begin{array}{l}\text { of Erasure } \\
\text { Cancellatior }\end{array}$ & $\begin{array}{l}\text { f Light } \\
\text { Marks }\end{array}$ \\
\hline $\begin{array}{l}\text { ery poor } \\
\text { oor } \\
\text { oor } \\
\text { oor }\end{array}$ & $\begin{array}{l}\text { excellent } \\
\text { excellent } \\
\text { excellent } \\
\text { excellent }\end{array}$ & $\begin{array}{l}\text { excellent } \\
\text { excellent } \\
\text { excellent } \\
\text { excellent }\end{array}$ \\
\hline
\end{tabular}

Resistance to Erasure of Regular to Heavy Cancellation Marks

fair to poor excellent excellent poor excellent poor excellent fair to poor excellent excellent excellent excellent 

Table 2. The effect of ink eradicators on light to medium and regular to heavy cancellation marks made with various cancellation inks on the Mail Order stamp.

Cancellation Ink

$\frac{\text { Regular }}{\text { resistance to eradication }}$

Light to Medium Cancellations

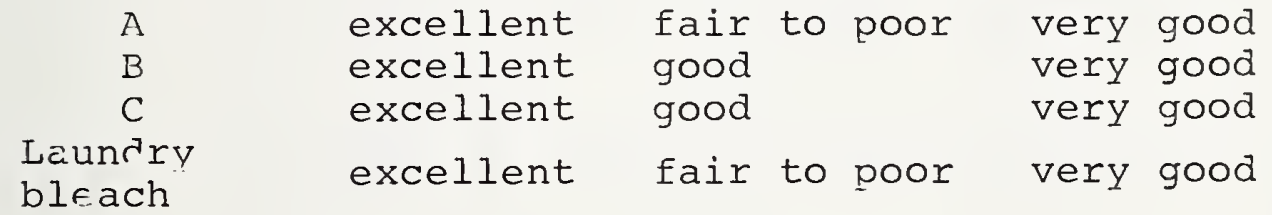

Regular to Heavy Cancellations

A

B

C

Laundry

bleach excellent fair

excellent fair

excellent fair

excellent fair very good very good very good very good 



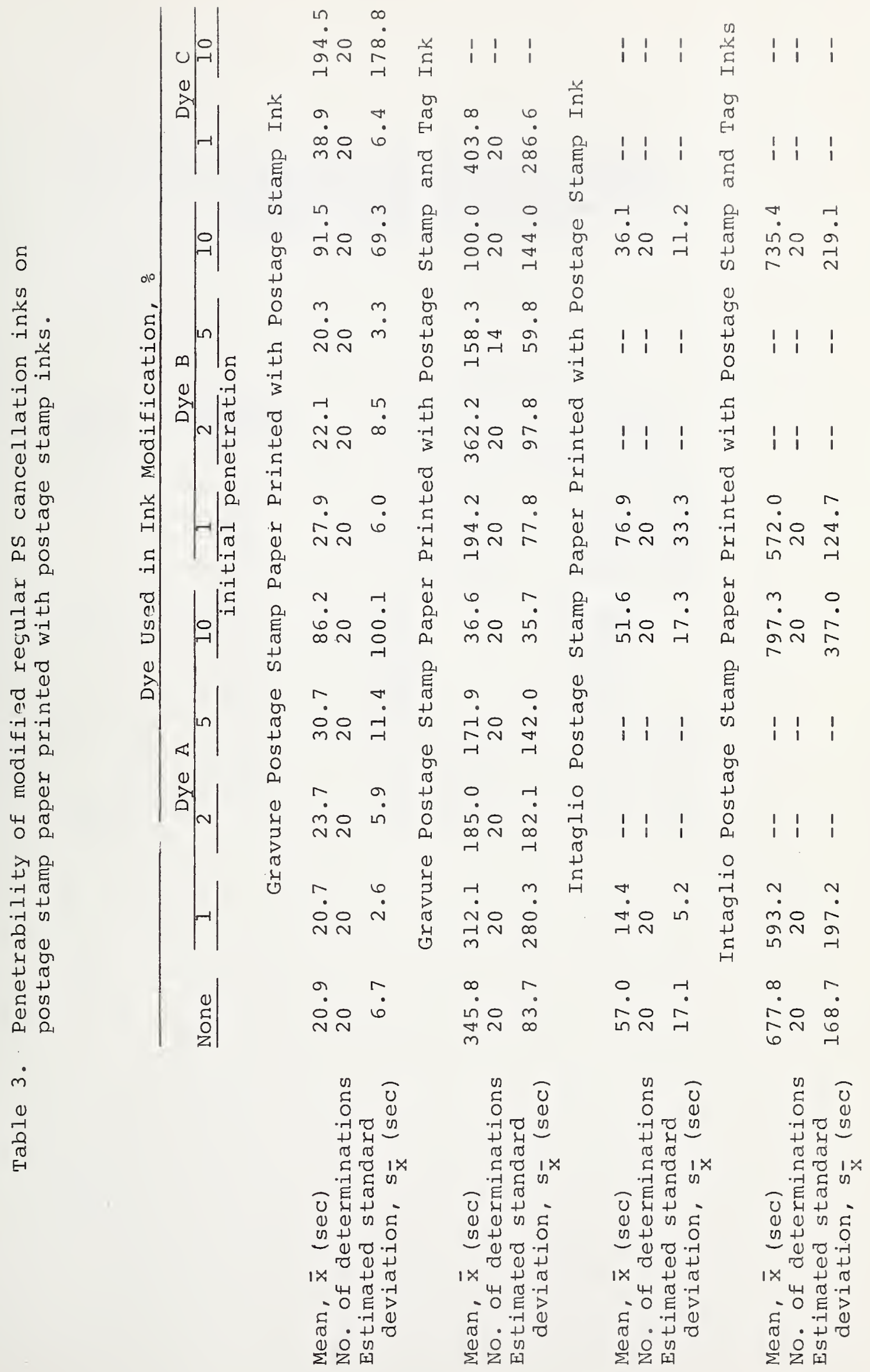


Table 4. Erasability of modified regular PS cancellation inks on gravure postage stamp paper printed with gravure postage stamp ink.

\begin{tabular}{|c|c|c|c|}
\hline \multirow[b]{2}{*}{ Dye } & \multirow{3}{*}{$\begin{array}{l}\text { Weight, } \\
\text { percent }\end{array}$} & \multicolumn{2}{|c|}{ Time, hrs. } \\
\hline & & 24 & 48 \\
\hline & & resistance & to erasure \\
\hline \multirow[t]{4}{*}{ A } & 1 & very good & very good \\
\hline & 2 & very good & very good \\
\hline & 5 & very good & very good \\
\hline & 10 & very good & very good \\
\hline \multirow[t]{4}{*}{ B } & 1 & poor & poor \\
\hline & 2 & poor & poor \\
\hline & 5 & poor & poor \\
\hline & 10 & poor & poor \\
\hline \multirow[t]{2}{*}{ C } & 1 & very poor & very poor \\
\hline & 10 & very poor & very poor \\
\hline none & & very poor & very poor \\
\hline
\end{tabular}



Table 5. Erasability of cancellation marks from lo0th Anniversary Mail Order stamp having light to medium and regular to heavy cancellation marks.

Time

hrs.

Cancellation Ink

Regular PS with

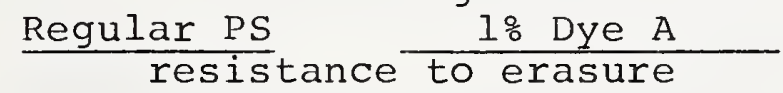

Light to Medium Cancellation Marks

2

24

48

72

very poor

very poor

very poor

very poor

very good

very good

very good

very good

Regular to Heavy Cancellation Marks

$\begin{array}{rll}2 & \text { poor } & \text { excellent } \\ 24 & \text { poor } & \text { excellent } \\ 48 & \text { poor } & \text { excellent } \\ 72 & \text { poor } & \text { excellent }\end{array}$



Table 6. The effect of ink eradicators on cancellation marks on the looth Anniversary Mail Order stamp having light to medium and regular to heavy cancellation marks. Eradicators were applied three times.

Cancellation Ink

Ink

Eradicator
A

B

C

$\mathrm{D}$

A
B
C
D
After

Before

Erasure

excellent excellent excellent excellent
Regular PS Regular PS with $1 \%$ Dye $A$

Light to Medium Cancellation Marks

\begin{tabular}{l} 
After \\
Erasure \\
\hline poor \\
poor \\
poor \\
poor
\end{tabular}

\begin{tabular}{lll}
$\begin{array}{ll}\text { Before } \\
\text { Erasure }\end{array}$ & & $\begin{array}{c}\text { After } \\
\text { Erasure }\end{array}$ \\
\cline { 1 - 1 } excellent & & good \\
excellent & good \\
excellent & fair \\
excellent & fair
\end{tabular}

Regular to Heavy Cancellation Marks

$\begin{array}{lll}\text { A } & \text { excellent } & \text { fair to poor } \\ \text { B } & \text { excellent } & \text { fair to poor } \\ \text { C } & \text { excellent } & \text { fair to poor } \\ \text { D } & \text { excellent } & \text { poor }\end{array}$

excellent excellent excellent excellent

excellent excellent excellent excellent 

Table 7. The effect of water soaking on cancellation marks on the looth Anniversary Mail Order stamp having light to medium and regular to heavy cancellation marks.

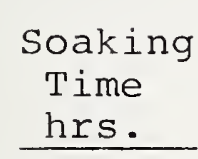

$1 / 4$

24

$1 / 4$

24
Cancellation Ink

Regular PS with

Regular PS

1\% Dye A

Light to Medium Cancellations

no effect

no effect

no effect

no effect

Regular to Heavy Cancellations

no effect

no effect

no effect

no effect 



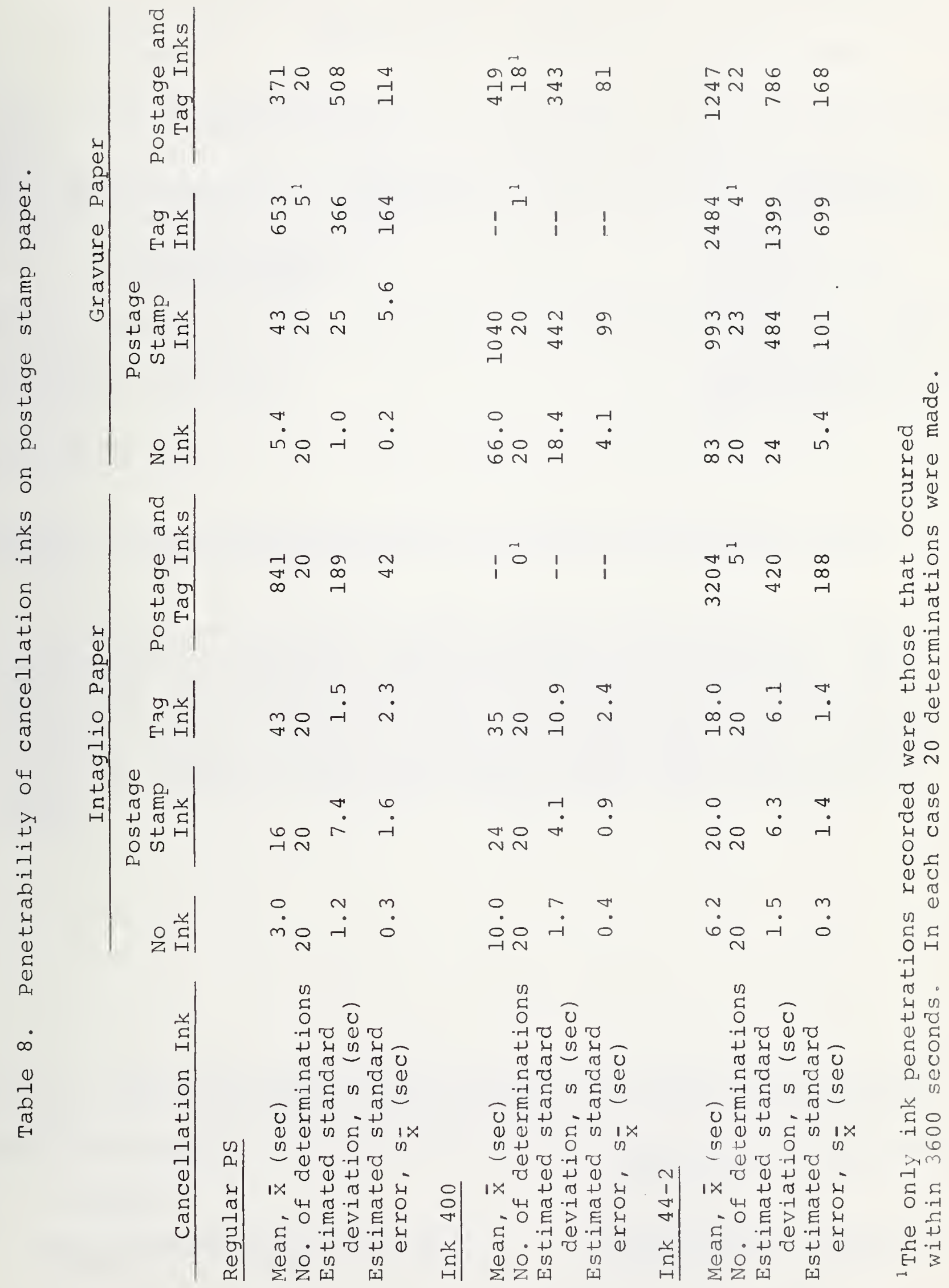



FORM PIF:-114A

\begin{tabular}{|c|c|c|}
\hline $\begin{array}{c}\text { U.S. DEPT. OF COMM. } \\
\text { BIBLIOGRAPHIC DATA } \\
\text { SHSET }\end{array}$ & $\begin{array}{r}\text { PUBLICATION OR KEPURT NO. } \\
\text { NBSIR 73-194 }\end{array}$ & $\begin{array}{l}\text { 2. (iOV'T AECESSION } \\
\text { Y.o. }\end{array}$ \\
\hline
\end{tabular}

4. TIT LE AND SUBTITLE

Performance of Cancellation Inks on Partially Tagged Gravure Postage Stamps

7. AUTHOR(S)

E. I.. Graminski and M. R. Brockman

9. PERFORMING ORGANIZATION NAME AND ADDRESS

NATIONAL BUREAU OF STANDARDS

DEPARTMENT OF COMMERCE

WASHINGTON, D.C. 20234

12. Sponsoring Organization Name and Address

U.S. Postal Service

Washington, D.C. 20260
3. Recipient's Accession :ío.

5. Publication Date

6. Performing Organization Code

8. Performing Organization NBS IR 73-194

10. Project/Task/ W'ork Unit Io.

4110448

11. Contract/Grant No.

USPS/NBS 72-1-01619

13. Type of Report \& Period Covered Final Repor $9 / 3 / 72-3 / 3 / 73$

14. Sponsoring Agency Code

15. SUPPLEMENTARY NOTES

16. ABSTR.ACT (A 200-word or less factual summary of most significant informat ion. If document includes a significant bibliography or literature survey, mention it here.)

The ink used in tagging postage stamps by the gravure printing process causes cancellation inks to perform unsatisfactorily. The impervious film formed by the tag ink retards or prevents penetration of ink vehicle and pigment into the stamp and also results in a smooth stamp surface which causes cancellation marks to be easily removed by erasure. Means for improving cancellation ink performance on gravure stamps have been found which involve modification of the cancellation inks and incomplete coverage of tag inks on gravure stamps.

17. KEY WORDS (Alphabetical order, separated by semicolons) Cancellation ink; gravure postage stamps; ink erasure test; ink modification; ink penetration test; tag ink

18. AVAILABILITY STATEMENT

19. SECURITY CLASS (THIS REPORT)

UNL IMIT ED.

ZX FOR OFFICIAL DISTRIBUTION. DO NOT RELEASE TO NTIS.

UNCL ASSIF IED

20. SECURITY CLASS (THIS PAGE)

UNCL ASSIFIED
21. NO. OF PAGES

22. Price

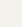




